\title{
Building Bridges: Opportunities and Challenges in Aboriginal Recruitment and Retention
}

\author{
Isobel M Findlay ${ }^{1^{*}}$ and Amy DM Andrew ${ }^{1}$ \\ ${ }^{1}$ Department of Management and Marketing, Edwards School of Business, University of Saskatchewan, Saskatoon, Canada
}

\section{Introduction}

Although supportive legislation has been enacted for over 30 years (Employment Equity Act, 1986, rev. 1995), deficits in employment participation, occupational and educational attainment, wages and opportunity remain for Aboriginal people (First Nations, Métis, and Inuit) and other equity groups in Canada [1,2]. As Saha et al. [3] suggest, "legislation alone is insufficient-mindsets of the key HR/ business people often matter more". In this context, this editorial reports on a qualitative study based on literature review and five key informant interviews with managers from the public, private, and co-operative, and labour sectors in Saskatchewan, Canada. Participants and organizations were purposefully recruited based on managerial responsibilities for diversity strategy and maturity of the program. The interviews focused not on evaluating the programs, policies, and organizations but on learning from each in developing recommendations for best practices for Aboriginal recruitment and retention. The study addresses these issues in a business environment facing labour shortages and population trends, including an aging workforce and growing Aboriginal population, all of which make Saskatchewan an important testing ground for strategies to support Aboriginal recruitment and retention [4].

\section{Diversity as a Competitive Advantage}

Research shows both the high costs of failure and the benefits of effectively engaging diversity. For example, the Toronto Board of Trade [5] estimated that Toronto alone loses as much as $\$ 2.25$ billion from its economy each year by failing to create an inclusive workforce and engage qualified, diverse candidates. If the Aboriginal population could reach the same level of education and social well-being as their nonAboriginal counterparts, Canada's GDP could be expected to rise by $\$ 401$ billion by 2026 [6]. Closing the education gap between Aboriginal and non-Aboriginal people could bring "a total social benefit" of $\$ 90$ billion to Saskatchewan, or a fifth more than the $\$ 72.2$ billion total production of a major economic player, the potash industry in Saskatchewan [4]. In addition, research shows a positive correlation between investment in diversity, sales revenue, and profitability [7]. According to Winston [2], as well as "higher quality decision making" and "an enhanced ability to target various segments of the market," the most diverse companies "based on factors such as minority employment at all levels, including senior management... have also been identified as more successful companies overall". By increasing Aboriginal diversity, organizations could be more successful in meeting the needs of their organization, of the Aboriginal population, while increasing their potential to become leaders in the growing national Aboriginal market $[8,9]$.

\section{Employment Equity}

Despite achievements of the Employment Equity Act, employment gaps remain for the designated groups $[8,10,11]$. Limitations of the program, including the lack of focus on changing organizational policies and structure, were dealt with in the 1995 program revisions, but the program still does little to effectively change systemic discrimination and organizational culture $[8,12,13]$. Enforcement remains an issue without a binding system of monitoring and compliance, relying solely on an annual report; and its narrow scope regulates employers only in the federal sector [10-12,14].

Despite Canadian values of diversity and multiculturalism, Employment Equity policies have met resistance based on political ideology and a "white male backlash" similar to that against Affirmative Action in the United States, even if on a considerably smaller scale $[8,11,14]$. A concern regarding Employment Equity legislation is its effectiveness in adapting to the changing nature of employment, including non-traditional and temporary employment with the targeted populations $[10,12]$.

\section{Diversity Management}

Managing diversity, a management construct $[15,16]$ focused on manager and staff interactions to change attitudes and behavior, may be effective in evading political criticism and backlash, but it may have little effect on a fair and representative workforce $[8,13,16]$. A major limitation is that programs often understand diversity from a white privileged perspective $[13,15,16]$. According to Agocs and Burr [8], "The beneficiaries of many diversity programs are clearly intended to be white able-bodied males, who are helped through the training to feel more comfortable with those who are different". This emphasis perpetuates the invisibility of normative white privileges and backlash against "special treatment" for diverse individuals. In addition, these programs are often pursued as a quick-fix for the benefits of a diverse workforce $[8,13,15,16]$. In sum, simply managing diversity risks forgetting and trivializing the historical injustices and inequalities faced by protected groups $[13,16]$.

\section{Burden of Accommodation/Epistemological Barriers}

A major shortcoming is that the burden of providing this education has traditionally fallen on diverse already disadvantaged individuals [17]. No white male is asked to explain the actions of all white males and act as an educator for their 'race.' A primary limitation is the "lens of whiteness," an epistemological barrier whereby white people think their institutions, norms, and practices the "correct" way, or simply "the way it is," rather than a construction of European culture that systematically discriminates against people of diverse backgrounds

*Corresponding author: Isobel M Findlay, Professor, Department of Management and Marketing, Edwards School of Business, PotashCorp Centre, University of Saskatchewan, 25 Campus Drive, Saskatoon, Canada, Tel: (306) 966-2385; E-mail: findlay@edwards.usask.ca

Received February 26, 2014; Accepted February 28, 2014; Published March 03 2014

Citation: Findlay IM, Andrew ADM (2014) Building Bridges: Opportunities and Challenges in Aboriginal Recruitment and Retention. J Bus Fin Aff 3:e142 doi:10.4172/2167-0234.1000e142

Copyright: (c) 2014 Findlay IM. This is an open-access article distributed under the terms of the Creative Commons Attribution License, which permits unrestricted use, distribution, and reproduction in any medium, provided the original author and source are credited. 
$[18,19]$. As a result of this unnoticed lens, though there may be no intent to discriminate, barriers to employment persist [20]. Taboos around race and discrimination mean that these subjects are neglected [21].

By challenging habitual policies and systems, learning about historical colonial relationships, and ensuring that white privilege and disadvantage are not trivialized, businesses and their managers can use their privilege to build diversity as a core competency of their organization $[18,19]$

\section{Findings and Discussion}

A summary of the participants, date of program initiation, sector, and motivations for development of the Aboriginal employment program, and key findings from each are included in Table 1.

One recurring theme is the value of partnering with the community and engaging in two-way communication for insight into the needs and realities of the Aboriginal community and for feedback on an organization's initiatives. Partnerships are essential in breaking down systemic discrimination and unpacking historical injustices. Another issue raised by all participants was the importance of preventing backlash by ensuring the perceived "fairness" of opportunities and programs: making programs and benefits available to all employees and stressing merit as the top requirement for employment and retention.

To address gaps in education and qualification of Aboriginal persons while maintaining the legitimacy of the program, most organizations suggested partnerships with community and educational institutions to implement scholarships, training programs, and experience for students. This allows each partner to use core capacities and knowledge to address the needs of the organization and the Aboriginal community. Going to the root of socio-economic inequalities also ensures that more qualified Aboriginal candidates are engaged in the workplace.
This insight goes to the heart of one participant's suggestion to "make program investments work" to create gains for society as a whole.

While there are many ways to be welcoming to Aboriginal employees, an emerging practice is to integrate the organization's goals for Aboriginal inclusion with the overall business strategy. Organizations can thus ensure that the structure and the culture of the organization reflects those goals, communicates them as a business imperative, receives support from all levels, and is considered in all decisions. Motivational and influential leadership, human and financial resources, and business imperatives such as labour requirements, all impact the success.

\section{Best Practices for Aboriginal Recruitment and Retention}

- Approaches that are integrated into the overall business strategy are more effective than "add-on" programs, which tend to have marginalized human and financial resources.

- To break down systemic \& epistemological barriers, awareness is needed of the cultures of Aboriginal peoples and mainstream society, and especially the assumptions, privileges, and daily accommodations of mainstream culture.

- With education about our own and others' histories, as well as current realities, organizations have the ability to get beyond comfort with others' differences to recognize and celebrate diversity-and realize gains associated with the business case for diversity.

- Educating the workforce about the realities of diversity programs, exposing myths about them, and challenging the "lens of whiteness" in mainstream culture is essential.

- Building legitimate relationships, partnerships and open, honest, two-way communication with communities allows each to use

\begin{tabular}{|c|c|c|c|}
\hline Name \& Program Initiation & Sector & Motivation of Development & - Key Findings \\
\hline Participant A, 2005-2006 & Cooperative, Partly Unionized & Community Mindset, Business Case & $\begin{array}{l}\text { - Mentorship Program } \\
\text { - } \text { Impact of Unionization }\end{array}$ \\
\hline Participant B, 1995 & Public, Union & Ministry \& Board Initiative & $\begin{array}{l}\text { Creating Culturally Competent } \\
\text { Organization } \\
\text { - } \quad \text { Better Meet Client Needs } \\
\text { - } \quad \text { Ualuing of Aboriginal Skills } \\
\text { - Union Influence }\end{array}$ \\
\hline Participant C, March 2010 & Private, Non-Unionized & Labour Requirements, Community Commitment & $\begin{array}{l}\text { - } \quad \text { No Constraining Legacy of } \\
\text { Program Business Strategy vs. } \\
\text { Diversity Program } \\
\text { - } \quad \text { Employment \& Supply Sides } \\
\text { - } \quad \text { Building Overall Talent pool } \\
\text { - } \quad \text { Significant Resources }\end{array}$ \\
\hline Participant D, Dec. 2009 & Public, Unionized & Employment Equity, Key Leadership Influence & $\begin{array}{ll}\text { - } & \text { Ministerial Objective } \\
\text { - } & \text { Influential Leadership } \\
\text { Changing Organizational } \\
\text { Behaviour } \\
\text { Balance with Visible Minority } \\
\text { Policy }\end{array}$ \\
\hline Participant E, N/A & Public & Demographic Reality, Social Pressure, Legislation & $\begin{array}{l}\text { Build a Reflective Workforce with } \\
\text { Aboriginal Managers } \\
\text { - Make Program Investments work } \\
\text { Don't Expect Conformity \& Be } \\
\text { Flexible } \\
\text { Teach the "Secret Handshake" of } \\
\text { Normalized Conventions }\end{array}$ \\
\hline
\end{tabular}

Table 1: Summary of The Participants And Key Findings 
Citation: Findlay IM, Andrew ADM (2014) Building Bridges: Opportunities and Challenges in Aboriginal Recruitment and Retention. J Bus Fin Aff 3:e142 doi:10.4172/2167-0234.1000e142

Page 3 of 3

its knowledge and core capacities to address the needs of each organization and establish trust.

- Truly successful strategies are unique and specific to the demographics of the local labour market and population, needs of the community, capabilities of the organization, and, perhaps most importantly, the historical relationships and context in which they are set.

\section{References}

1. Miller GE, Mills AJ, Mills H (2009) Introduction: Gender and diversity at work: Changing theories. Changing Organizations. Canadian Journal of Administrative Sciences. 26: 173-175.

2. Winston $M(2008)$ Diversity: the research and the lack of progress. New World Library 109: 130-149.

3. Saha SK, O'Donnell D, Patel T, Heneghan J (2008) A study of individual values and employment equity in Canada, France, and Ireland. Equal Opportunities International 27: 629-645.

4. Howe E (2011) Bridging the Aboriginal education gap in Saskatchewan. Saskatoon: Gabriel Dumont Institute.

5. Toronto Board of Trade (2010) Pushing the boundaries: Advancing civic leadership for regional prosperity. Toronto, ON, Canada.

6. Lendsay K (2011) Aboriginal inclusion wise policy. The Star Phoenix.

7. Herring C (2009) Does diversity pay? Race, gender, and the business case for diversity. American Sociological Review 74: 208-224.

8. Agocs C, Burr C (1996) Employment equity, affirmative action and managing diversity: Assessing the differences. International Journal of Manpower 15: 3045.

9. Anderson T (2010) 2006 Aboriginal population profile for Saskatoon. Statistics Canada 89-638-X-Number 5.
10. Jain HC, Lawer JJ, Bai B, Lee EK (2010) Effectiveness of Canada's employment equity legislation for women (1997-2004): Implications for Policy Makers. Relations Industrielles 65: 304-329.

11. Mighty JE (1996) Factors affecting the adoption of employment equity: An example from Canada. Equality, Diversity and Inclusion: An International Journal 15: 1-27

12. Agocs C (2002) Canada's employment equity legislation and policy, 19872000: The gap between policy and practice. International Journal of Manpower 23: $256-276$

13. Kirby EL, Harter LM (2003) Speaking the language of the bottom-line: The metaphor of "managing diversity". The Journal of Business Communications 40: $28-49$

14. Mentzer MS (2002) The Canadian experience with employment equity legislation. International Journal of Value - Based Management, 15: 35-50

15. Bleijenbergh I, Peters P, Poutsma E (2010) Diversity management beyond the business case. Equality, Diversity and Inclusion: An International Journal 29 413-421.

16. Heres L, Benschop Y (2010) Taming diversity: An exploratory study on the travel of a management fashion. Equality, Diversity and Inclusion: An International Journal, 29: 436-457.

17. Lai DW, Huffey N (2009) Experience of discrimination by visible minorities in small communities. Our Diverse Cities. 2: 124-129.

18. Banerjee S, Tedmanson D (2010) Grass burning under our feet: Indigenous enterprise development in a political economy of whiteness. Management Learning. 41: 47-65.

19. McIntosh P (1990) White privilege: Unpacking the invisible knapsack. Independent School 49.

20. Carr PR (2008) The "equity waltz" in Canada: Whiteness and the informal realities of racism in education. Journal of Contemporary Issues in Education 3: $4-23$

21. Khan C (2006) "The blind spot": Racism and discrimination in the workplace. Our Diverse Cities, 2: 61- 65. 